Luís Inácio

\title{
O que é Design de Informação?
}

What it is Information Design?

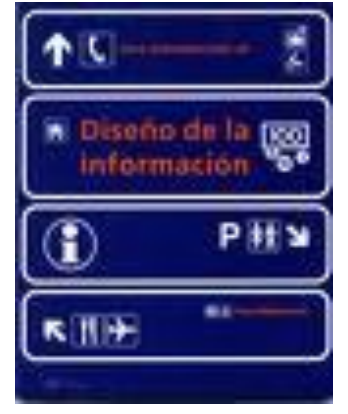

\author{
Paul Mijksenaar, Una Introducción al \\ Diseño de la Información, Editorial Gustavo e \\ Gili, SA de CV, México 2001, 56pp, (ISBN: 968- 887- \\ 389-6).Título original: Visual Function. An \\ Introduction to Information Design, tradução \\ castelhana de Andreu Cabré, 2001
}

\begin{abstract}
Mijksenaar, design, informação, introdução.
Una Introducción al Diseño de la Información da autoria de Paul Mijksenaar, pretende dar uma visão sucinta mas muito erudita do campo do Design de Informação. Este livro abrange uma análise a todas a valências desta disciplina, incluindo as discussões teóricas sobre a análise da informação e sua respectiva claridade para o utilizador, como também uma breve perspectiva histórica. Isto complementado com inúmeras ilustrações que demonstram este campo.
\end{abstract}

Mijksenaar, design, information, introduction.

Una Introducción al Diseño de la Información from the author Paul Mijksenaar, aspires to give a brief but very erudite view of the field of Information Design. This book supports a wide analysis of all valences of this discipline, this includes the theoretical discussion about information analysis and its clarity to the user, as well as a brief historical perspective. This is complemented with numerous illustrations that are demonstrative of this field.

\section{O que é Design de Informação?}

Esta é uma pergunta que o livro Una Introducción al Diseño de la Información da autoria de Paul Mijksenaar, professor da Universidade de Tecnologia de Delft, pretende responder. Utilizando o livro como um preâmbulo ao Design de Informação (DI), este tem como objectivo o de divulgar, revelar e emancipar a essência que move esta disciplina, e consegue-o explanando as perspectivas históricas e teóricas de uma maneira concisa, clara, e erudita. Para isso, Mijksenaar alinha a construção deste pequeno livro através de três linhas gerais: a perspectiva ontológica, teleológica, e histórica do DI.

\section{Perspectiva ontológica}

Na perspectiva ontológica Mijksenaar começa por demonstrar que, as necessidades do ser humano em apresentar de uma maneira acessível a informação, são essenciais para o crescimento cognitivo da cultura social, mas que na maior parte dos casos isso não é feito ou 


\section{Infodesıgn}

alcançado, deturpando o próprio fim dessas ideais iniciais. Começa por isso a demonstrar exemplos de informação visual mal resolvida e/ou mal aplicada (i.e. através de situações de metodologias receituárias), apresenta também o problema da dicotomia design gráfico/DI, isto é, do antagonismo entre embelezamento e funcionalidade, e o problema premente do excesso de informação, indicando que estes problemas induzem ao erro de leitura e consequentemente ao erro cognitivo da informação disposta. Isto é tanto ou mais representativo se demonstrarmos como estas más configurações podem inibir o nível intelectual, de modo a afectar importantes decisões. Temos o exemplo do redesign do gráfico produzido pelo comité de investigadores do desastre de 1986 do vaivém Challenger, feito por Edward Tufte (p.7), que demonstra que numa apresentação mais clara dos mesmos dados o acidente poderia eventualmente ter sido evitado.

Nestes exemplos Mijksenaar demonstra que o DI é uma disciplina transversal, que além de trabalhar com vários campos como a ilustração, a fotografia, a cartografia, o design gráfico, design industrial, a arquitectura, a psicologia experimental, entre outros, enaltecendo a ideia de colaboração e de multidisciplinaridade, pode também fornecer ferramentas a todos esses campos para tomada de decisões. E por isso consequente a ideia da primazia do conteúdo sobre a forma, porque é com esse conteúdo diversificado e horizontal que o DI trabalha directamente. Isto introduz-nos para a noção que se defende ao longo de todo o livro e que se assume como linha condutora do DI, que é a necessidade da claridade da informação.

Aquilo que aparentemente pretende resolver um problema, não é mais do que uma cuidada análise dos dados, que são a base para qualquer construção de uma informação visual.

\section{Perspectiva teleológica}

Ontologicamente, Mijksenaar demonstra que o DI é sempre um exercício de conhecimento, e que é uma disciplina que tende a dominar o conteúdo e só depois, consequentemente, a forma. Esse domínio do conteúdo corrobora a tese da claridade como função primordial do DI provando que o acto não pode ser subordinado a receitas, mas sim a um espírito crítico e engenhoso, sem cair nas questões subjectivas do gosto ou do belo de uma forma. Por isso Mijksenaar argumenta que normalmente a grande maioria dos designers está mais preocupada com as suas expressões pessoais, com a sua criatividade e a experimentação, e não se preocupam com a claridade, isto faz com que a inovação fique de fora, sem ser considerada como um problema maior. Somos introduzidos assim, ao debate sobre a forma e função, e consequentemente, ao problema de que com que regras teleológicas o DI deve actuar. Mijksenaar apresenta-nos não só uma pequeníssima colocação histórica dessa discussão teórica e seus argumentos, como também uma possível metodologia para a distinção e elaboração do que é DI ou não, sempre com a ênfase no projecto último da claridade. Esta técnica, elaborada pelo arquitecto romano Vitruvius, baseia-se em três critérios, a saber, Firmitas (durabilidade, firmeza), Utilitas (utilidade, comodidade), e Venustas (beleza, prazer), demonstrando vários exemplos de como utilizar esta técnica de recurso para qualquer objecto, justificando as mais valias desta opção como método versátil, de modo que 'não é susceptível de gerar qualquer tipo de dogmas que possam conduzir a uma interpretação demasiado estrita' (p.20). A defesa da claridade não é só suportada com os argumentos da necessidade de vincular informação cada vez mais complexa, mas também com a funcionalidade e utilidade. Noção esta que é reforçada pela citação, feita por Mijksenaar, de Henry van der Velde 'A beleza é o resultado da clareza e do sistema (..) e não da ilusão óptica' (p.18), demonstrando assim a linha condutora deste livro (esta ideia é aliás partilhada por Edward Tufte, que vai mais longe e considera todo o grafismo que tenha o propósito de embelezar e não de ajudar analiticamente na descodificação dos dados, como chartjunk (Tufte, 1990)).

\section{Perspectiva histórica}

Este livro contextualiza a representação gráfica dentro do DI, fazendo uma breve introdução à história deste campo, apresentando-nos brevemente as sequências históricas desde os primeiros gráficos do bispo Lisieux, passando pelo sistema gráfico Cartesiano de Descartes, e enaltecendo historicamente os trabalhos do francês Joseph Minard, tal como os da enfermeira inglesa Florence Nightingale. Inicia-nos também à gramática de elementos básicos gráficos utilizada nas representações gráficas, estudadas pelo cartógrafo francês Jacques Bertin. Esta gramática proporciona 'aos designers um conjunto de directrizes inteligíveis e úteis' (p.39). Demonstra-nos também as novas tendências dentro da informação visual, e a sua utilização da fotografia, da linguagem da banda desenhada, da ilustração técnica, e da animação. Neste momento, e tomando essa liberdade de actualização das novas tendências dentro da visualização 
da informação, podemos considerar as ideias da programação informática e linguagens sobre a informação visual interactiva, e com o constrangimento de estas tendências o terem de ser actualizadas em tempo real. Onde temos, por exemplo, os estudos sobre gráficos em espaço hiperbólico 3D da Tamara Munzner, e a visualização orgânica da informação de Ben Fry (Fry, 2000; Munzner, 1998), entre outros.

\section{Una Introducción}

Embora a versão mexicana contenha algumas gralhas, por exemplo: aparecendo Henry Beck (pp. 5-6), em vez do realmente Harry Beck, como elaborador do mapa do Metro Underground de Londres; e, na p.17, onde se lê '... Em 1922, Edward Tufte concluiu, uma vez mais, que a estética é um efeito secundário da apresentação visual da informação...', induz em erro, sabendo que esta afirmação não é possível visto que Edward Tufte só nasceu em 1942. Isto em nada diminui o conteúdo íntegro deste livro. Una Introducción al Diseño de la Información é um livro que todos os designers deviam ter conhecimento, e segue uma linha já comum, por exemplo na área da Ciência, que são os livros de divulgação, acumulando com a função de introduzir aos designers e a curiosos, o campo do DI. Este livro espanta-nos cada vez que o abrimos, e realmente responde e contextualiza muitas questões, e incentiva à continuação da pesquisa no âmbito do DI, e da prática da claridade da informação. Este livro de bolso, é apenas a introdução para um mundo maior.

\section{Referências}

Fry, B. (2000), Ben Fry - página pessoal. Acedida a 30 de Julho de 2005, em: http://acg.media.mit.edu/people/fry/.

Munzner, T. (1998), Exploring Large Graphs in 3D Hyperbolic Space. Acedida a 30 de Julho de 2005, em: http://graphics.stanford.edu/papers/h3cga/.

Tufte, E. (1990), Envisioning Information, 9ª edição (2003), Graphics Press LLc, Connecticut

\section{Sobre o autor}

Luís Inácio nasceu em 1979, é licenciado em Design de Comunicação pela ARCA - EUAC Escola Universitária das Artes de Coimbra, cujos trabalhos finais revolveram à volta da visualização de informação conceptual. Administra desde Outubro de 2004 a publicação on-line sobre Design geral, a Desígnio, e desenvolve pesquisa de foro pessoal sobre a ontologia do Design e o seu comportamento Ético. 